\title{
Virtual screening for potential COX-inhibiting constituents from Mimosa pudica
}

\author{
Ashekul Islam ${ }^{1}$, Mohammad Shah Hafez Kabir ${ }^{2}$, Raju Dash ${ }^{3}$, Talha Bin Emran ${ }^{1,3}$, Md. Zia Uddin ${ }^{3}$, Khairun Nesa ${ }^{3}$, Mir \\ Muhammad Nasir Uddin ${ }^{4}$, Md. Tanveer Ahsan ${ }^{4 *}$ \\ ${ }^{1}$ Department of Biochemistry and Molecular Biology, University of Chittagong, Chittagong-4331, Bangladesh. ${ }^{2}$ Department of Pharmacy, International \\ Islamic University Chittagong, Chittagong, 4203, Bangladesh. ${ }^{3}$ Department of Pharmacy, BGC Trust University Bangladesh, Chittagong-4000, Bangladesh. \\ ${ }^{4}$ Department of Pharmacy, University of Chittagong, Chittagong-4331, Bangladesh.
}

\section{ARTICLE INFO \\ Article history: \\ Received on: 19/02/2015 \\ Revised on: 04/03/2015 \\ Accepted on: 18/05/2015 \\ Available online: $27 / 07 / 2015$}

Key words: Mimosa pudica, Analgesic, Antiinflammatory, COX, Vitexin, Mimosine.

\begin{abstract}
Developing a new agent in the anti-inflammatory and analgesic field, plants secondary metabolites can be a good source for the Non-Steroidal Anti-inflammatory Drugs (NSAID) drug development. For this purpose we subjected the active compounds of Mimosa pudica Linn. to reveal its potentiality by molecular docking analysis to find out its potent compound against COX which was done by GOLD docking analysis. Docking studies by GOLD showed that vitexin of Mimosa pudica had the highest fitness score against the COX-1 which is 60.43 and 63.49 for COX-2 enzyme. Vitexin of Mimosa pudica detected with significant fitness score and hydrogen bonding against COX-1 and COX-2 which may be a potent analgesic compound.
\end{abstract}

\section{INTRODUCTION}

Having the anti-inflammatory, analgesic and antipyretic effects, non-steroidal anti-inflammatory drugs (NSAIDs) form an important class of widely used therapeutic agents. Inflammation is a process involved in the pathogenesis of several disorders like arthritis and cardiovascular disease (Jiang and Ames, 2003). Cyclooxygenase (COX) is an endogenous enzyme which catalyses the conversion of arachidonic acid into prostaglandins and thromboxanes (Vane et al., 1998; Smith et al., 2000). The enzyme exists in at least two isoforms, COX-1 and COX-2. Although both the isoforms catalyze the same biochemical conversion, the two isoforms are subject to a different expression regulation (Smith- et al., 1993). COX-1 is a constitutive enzyme and is responsible for the supply of prostaglandins which maintain the integrity of the gastric mucosa and provide satisfactory vascular homeostasis whereas COX-2 is an inducible enzyme and is expressed only after an inflammatory stimulus (Kurumbail et al., 1996; Ishikawa et al., 2009). Literature studies indicate that direct tissue contact of NSAIDs

\footnotetext{
* Corresponding Author

Md. Tanveer Ahsan,

Email : tanveer.ahsan.fahim[at]outlook.com
}

gives the side effects like gastric upset, irritation, and ulceration (Lanza, 1998), and also confirms that gastrointestinal side effects of NSAIDs such as irritation and GI bleeding are due to the presence of a free carboxylic group in the parent drug (Husain et al., 2005; Metwally et al., 2007). Thus, developing new agents with minimum or without side effects is an extensive research area in the present scenario. To find out a potent anti-inflammatory compound and we chose Mimosa pudica L. commonly known as 'Lajjabati' belonging to the family Fabaceae, is a stout strangling prostrate shrubby plant with compound leaves, sensitive to touch, spinous stipules and globose pinkish flower heads. It grows in almost all parts of Bangladesh (Akter et al., 2010; Baghel et al., 2013; Malayan et al., 2013). It is originated in South America and naturalized almost throughout the tropical and subtropical parts of India (Akter et al., 2010). The plant is regarded as diuretic, astringent and antispasmodic. Leaves and roots are used in the treatment of piles and fistula. Paste of leaves is applied to hydrocele. Cotton impregnated with juice of leaves is used for dressing sinus. The plant is also useful in the treatment of sore gums and is used as a blood purifier (Vaidya and Sheth, 1986). It is also used for treating convulsions of children. Ethanolic extract of Mimosa pudica showed nootropic (cognition enhancement) activity in Wistar Albino Rats (Ayissi Mbomo et al., 2012) and also anti-helmintic (De Luccia, 2012). 
Various studies suggested that this plant have therapeutic activities such as urolithiasis, ovulation, vibriocidal, antidepressant, estrogenic and antiestrogenic activities, antiimplantation and antiestrogenic activity, effects on oestrous cycle and ovulation, hyperglycemic, anticonvulsant activity, hyaluronidase and protease activities (Sanberg, 1976; Molina et al., 1999; Ngo Bum et al., 2004; Ganguly et al., 2007; Kokane et al., 2009; Ahmad et al., 2012). However, the analgesic and antiinflammatory activity of Mimosa pudica has been established reported in earlier studies (Ayissi Mbomo et al., 2012). Various literature suggested that Mimosa pudica contain compounds like Crocetin, Mimosine, Norepinephrine, Thiamin (Ahmad et al., 2012), Turgorin (Varin et al., 1997), Isorientin, Orientin, Isovitexin, Vitexin (Zhang et al., 2011), D-pinitol, Jasmonic acid (Tsurumi and Asahi, 1985) and Quercetin (Shrinivasan et al., 2012). This work was aimed to describe described the antiinflammatory and analgesic activity of Mimosa pudica by in silico molecular docking analysis to find out the novel compound having the inhibitory activity against COX-1 and COX-2 enzymes. The docking analysis involves the prediction of ligand conformation and orientation (or posing) within a targeted binding site. In the main, there are two aims of docking studies: accurate structural modeling and correct prediction of activity. However, the identification of molecular features that are responsible for specific biological recognition, or the prediction of compound modifications that improve potency, are them are much more focused on capturing energetic than entropic effects (Kitchen et al., 2004; Dash R, 2014).

\section{MATERIALS AND METHODS}

\section{Ligand preparation}

From the literature review, all compounds, Crocetin, Mimosine, Norepinephrine, Thiamin, Turgorin, Isorientin, Orientin, isovitexin, Vitexin, D-pinitol, Jasmonic acid and Quercetin was drawn in Symyx Draw 4.0 represented in figure 1 and then prepared for docking using the Sybyl 7.3 Molecular Modeling Suite of Tripos, Inc. 3D conformations (here only shows 2D structures) were generated using Concord 4.0 (Hevener et al., 2009), hydrogen atoms were added and charges were loaded using the Gasteiger and Marsili charges calculation method (Hristozov et al., 2007).

The ligand were minimized with the Tripos Force Field prior to docking using the Powell method with an initial Simplex (Osolodkin et al., 2011) optimization and 1000 iterations or gradient termination at $0.01 \mathrm{kcal} /\left(\mathrm{mol}^{*} \mathrm{~A}\right)$. Input ligand file format was mol 2 for all docking programs investigated.

\section{Protein preparation and active site determination}

The crystal structure COX-1 and COX-2 enzymes were collected protein data bank (Berman et al., 2000) pdb id: 2OYE (COX-1) and $6 \mathrm{COX}(\mathrm{COX}-2)$. Two enzymes were prepared according to the docking protocol of GOLD. The active site of these enzyme were identified according to the giving information by Harman et al. 2007 (Harman et al., 2007) for COX-1 and Kurumbail et al., 1996 (Kurumbail et al., 1996) for COX-2.
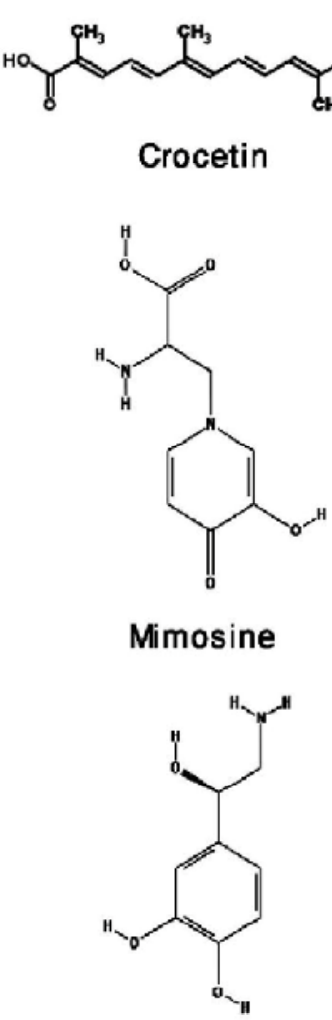

Norepinephrine

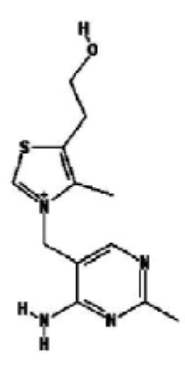

Thiamin

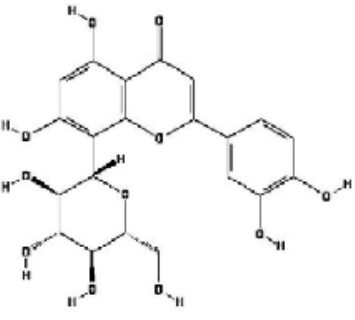

Orientin
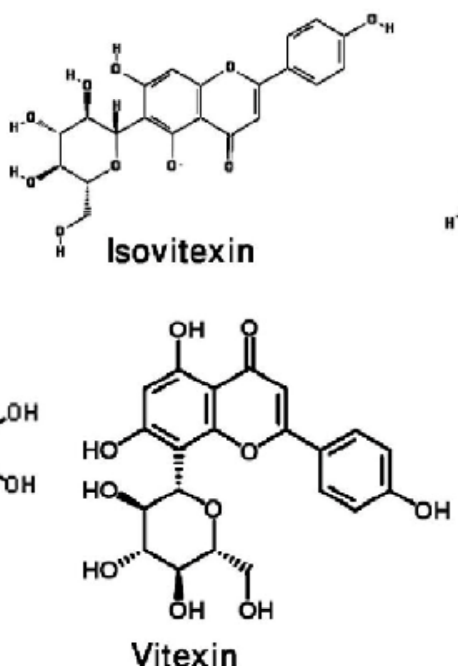

Vitexin<smiles>CO[C@@H]1[C@H](O)[C@@H](O)[C@H](O)[C@@H](O)[C@H]1O</smiles><smiles>CCC(N)=C(N)C[C@H]1C(=O)CC[C@@H]1CC(=O)O</smiles>

Jasmonic acid<smiles></smiles>

Quercetin

Fig. 1: Two-dimensional structure of all compounds isolated from Mimosa pudica 
Table 1: Gold fitness score of all compounds of Mimosa pudica against COX-1 and COX-2 protein.

\begin{tabular}{|c|c|c|c|c|c|c|c|c|c|c|}
\hline \multirow{2}{*}{ Compounds Name } & \multicolumn{5}{|c|}{ COX-1 } & \multicolumn{5}{|c|}{ COX-2 } \\
\hline & Gold Fitness & S(hb_ext) & S(vdw_ext) & S(hb_int) & S(int) & Gold Fitness & S(hb_ext) & S(vdw_ext) & S(hb_int) & S(int) \\
\hline Crocetin & 35.82 & 0.01 & 44.88 & 0.00 & -25.90 & 34.33 & 0.00 & 43.70 & 0.00 & -25.77 \\
\hline Mimosine & 36.04 & 2.59 & 28.40 & 0.00 & -5.60 & 36.39 & 9.01 & 24.17 & 0.00 & -5.85 \\
\hline Norepinephrine & 33.26 & 2.61 & 27.53 & 0.00 & -7.20 & 32.32 & 2.37 & 26.66 & 0.00 & -6.70 \\
\hline Thiamin & 51.33 & 3.36 & 38.76 & 0.00 & -5.32 & 50.36 & 1.95 & 40.88 & 0.00 & -7.80 \\
\hline Turgorin & 50.50 & 7.68 & 41.62 & 0.00 & -14.42 & 58.04 & 12.84 & 43.19 & 0.00 & -14.19 \\
\hline Isorientin & 44.11 & 2.93 & 41.11 & 0.00 & -15.34 & 36.01 & 1.83 & 36.55 & 0.00 & -16.07 \\
\hline Orientin & 38.84 & 1.85 & 38.59 & 0.00 & -16.06 & 32.02 & 4.09 & 42.16 & 0.00 & -30.04 \\
\hline Isovitexin & 46.70 & 1.08 & 41.96 & 0.00 & -12.08 & 44.37 & 9.10 & 51.02 & 0.00 & -34.88 \\
\hline Vitexin & 60.43 & 3.76 & 49.93 & 0.00 & -11.98 & 63.49 & 7.54 & 50.85 & 0.00 & -13.97 \\
\hline D-pinitol & 30.78 & 4.31 & 23.70 & 0.00 & -6.12 & 30.82 & 1.98 & 24.08 & 0.00 & -4.28 \\
\hline Jasmonic acid & 37.40 & 0.00 & 31.17 & 0.00 & -5.45 & 41.76 & 6.00 & 30.15 & 0.00 & -5.70 \\
\hline Quercetin & 48.53 & 5.36 & 40.20 & 0.00 & -12.11 & 45.44 & 8.82 & 36.19 & 0.00 & -13.15 \\
\hline Crocetin & 35.82 & 0.01 & 44.88 & 0.00 & -25.90 & 34.33 & 0.00 & 43.70 & 0.00 & -25.77 \\
\hline
\end{tabular}

Table 2: Protein Ligand Interaction of vitexin with COX

\begin{tabular}{cccc}
\hline & COX-1 & & COX-2 \\
\hline Interacted Amino acid residue & Hydrogen bond Distance $(\AA)$ & Interacted Amino acid residue & Hydrogen bond Distance $(\AA)$ \\
SER 530 & 2.904 & SER 530 & 2.722 \\
TYR 385 & 2.747 & SER 530 & 2.682 \\
SER 530 & 2.048 & TYR 385 & 2.349 \\
& & TYR 355 & 2.275 \\
& & ARG 120 & 3.055 \\
\hline
\end{tabular}

\section{Docking using GOLD (Genetic Optimization for Ligand Docking)}

GOLD utilizes genetic algorithm to explore the rotational flexibility of receptor hydrogens and ligand conformational flexibility (Jones et al., 1997). In GOLD docking was carried out using the wizard with default parameters population size (100); selection pressure (1.1); number of operations (10,0 00); number of islands (1); niche size (2); and operator weights for migrate (0), mutate (100), and crossover (100) were applied. The active site with a $10 \AA$ radius sphere was defined by selecting an active site residue of protein.

Default Genetic Algorithm settings were used for all calculations and a set of 10 solutions were saved for each ligand. GOLD was used by a GoldScore fitness function. GoldScore is a molecular mechanism like function and has been optimized for the calculation of binding positions of ligand. It takes into account four terms:

Fitness $=S_{(\text {hb_ext })}+1.3750 * S_{\left(v d w \_e x t\right)}+S_{\left(h b \_ \text {int }\right)}+1.0000 * S_{(\text {int })}$

$S_{(\text {int })}=S_{(\text {vdw_int) }}+S_{(\text {tors })}$

Where, $S_{h b \_e x t}$ is the protein-ligand hydrogen bonding and $s_{\mathrm{vdw}_{-} \text {ext }}$ are the vanderwaals interactions between protein and ligand. $S_{\mathrm{hb} \text { _int }}$ are the intramolecular hydrophobic interactions where as $S_{\mathrm{vdw}_{-} \text {int }}$ is the contribution due to intra molecular strain in the ligand (Uddin et al., 2014).

\section{RESULTS}

After preparing the compounds of Mimosa pudica mentioned above were subjected to dock in the active site of COX1 and COX-2 enzyme by GOLD docking method. The results of docking analysis are listed in Table 1. After docking the ligand protein complex having best fitness score was saved in pdb format than subjected to be analyzed in the Accelrys Discovery Studio
Visualizer and result of protein and ligand interactions are listed in Table 2. Docking studies showed that vitexin had the best gold fitness score against the COX-1 which was 60.43 and 63.49 for.

\section{DISCUSSION}

Advances in computational techniques have enabled virtual screening to have a positive impact on the discovery process. Virtual screening utilizes docking and scoring of each compound from a dataset and the technique used is based on predicting the binding modes and binding affinities of each compound in the dataset by means of docking to an X-ray crystallographic structure (Franca et al., 2013). To identify a potential analgesic lead molecule, we have subjected the docking analysis of the active compounds of Mimosa pudica to the active site cyclooxygenase enzymes viz. COX-1 and COX-2. Gold fitness score suggested that vitexin had the highest affinity to the COX-1 and COX-2 enzymes corresponding to the other compounds. Literature based studies suggested that several structural features are considered to be an important for efficient COX inhibition: (i) a carboxylate moiety that interacts with the Arg 120 side chain; (ii) a carbonyl moiety that interacts via a hydrogen bond with the side chain of Ser 530 and (iii) a distal aromatic ring filling a hydrophobic pocket beneath the Tyr 385 side chain (Luong et al., 1996; Llorens et al., 2002; Pouplana et al., 2002; Michaux and Charlier, 2004). Protein ligand interaction of vitexin with COX-1 and COX-2 represented in Table 2 and shown in Figure 2 and 3 has been postulated that vitexin has the enzyme catalysis activity in two enzymes but active in COX-2 enzyme due to formation of three hydrogen bonds with three residues Arg 120, Tyr 385 and Ser 530 which lead to process antiinflammatory action by inhibiting biosynthesis of prostaglandins and thromboxanes from arachidonic acid. 


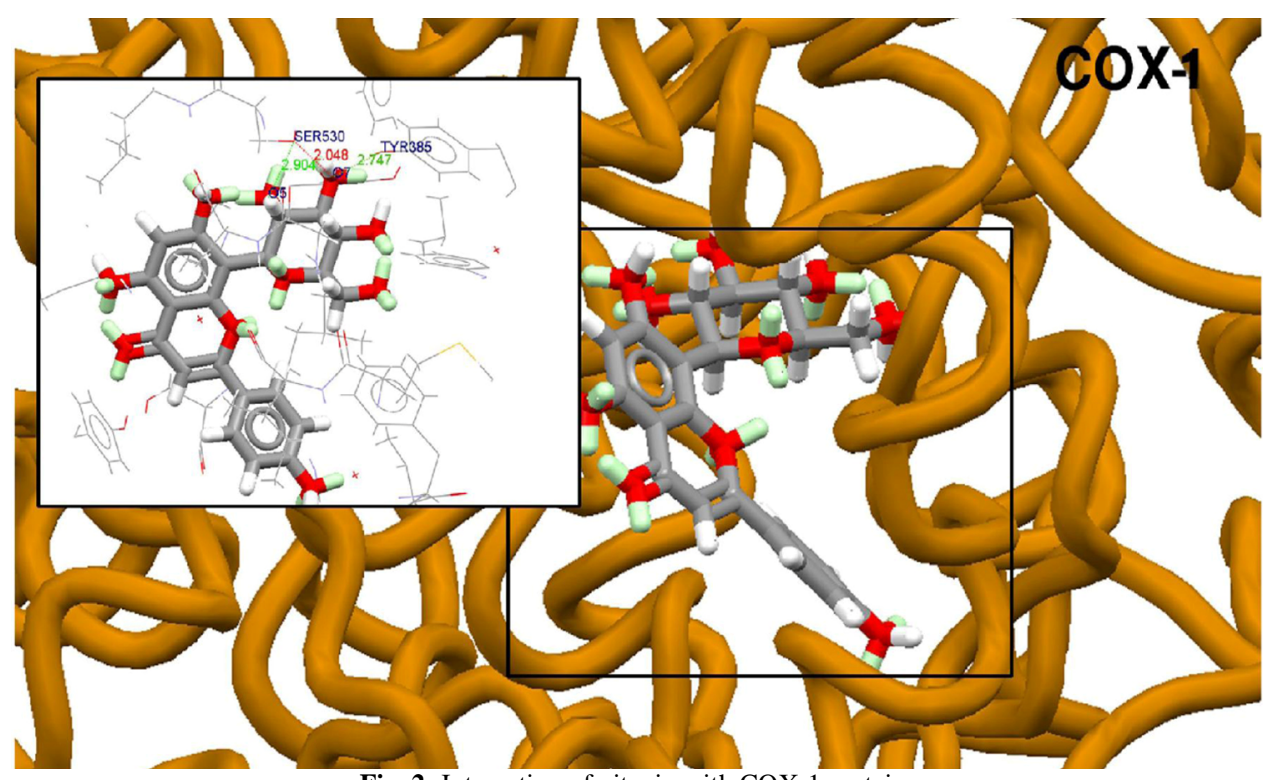

Fig. 2: Interaction of vitexin with $\mathrm{COX}-1$ protein

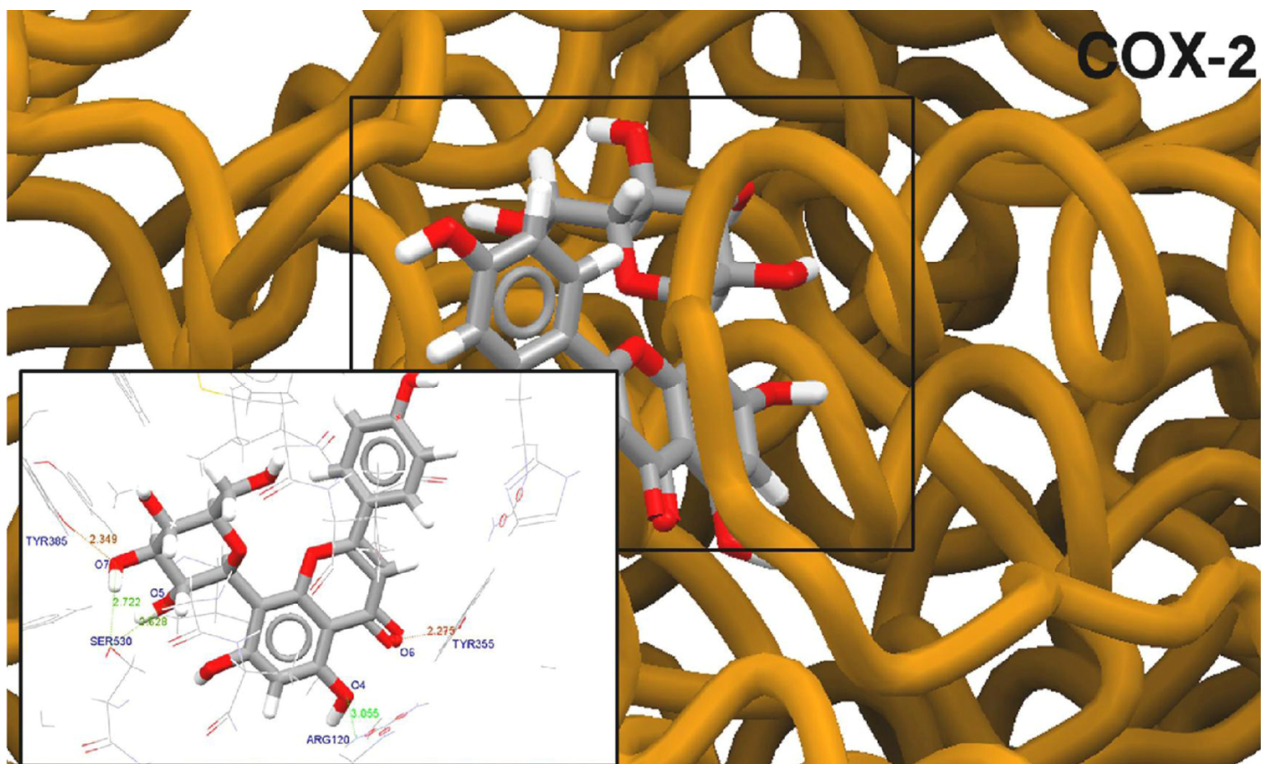

Fig. 3: Interaction of vitexin with $\mathrm{COX}-2$ protein

\section{CONCLUSION}

The present study revealed that Mimosa pudica has the compound named vitexin, which had the highest analgesic activity. Isolation of this compound will be imported to test the effectiveness of this compound and also its ADME profile for social benefit thus reducing the time and cost in drug discovery process.

\section{ACKNOWLEDGEMENTS}

The authors wish to thank Mr. Zahed Bin Rahim, Assistant Professor, Department of Pharmacy, BGC Trust University Bangladesh, Chittagong-4000, Bangladesh for his continuous support in performing this experiment.

\section{COMPETING INTERESTS}

All authors declare that they have no competing interests.

\section{REFERENCES}

Ahmad H, Sehgal S, Mishra A, Gupta R. Mimosa pudica L. (Laajvanti): An overview. Pharmacogn Rev. 2012; 6: 115-24.

Akter A, Neela FA, Khan MS, Islam MS, Alam MF. Screening of ethanol, petroleum ether and chloroform extracts of medicinal plants, Lawsonia inermis $\mathrm{L}$ and Mimosa pudica $\mathrm{L}$ for antibacterial activity. Indian J Pharm Sci. 2010; 72: 388-92.

Ayissi MR, Gartside S, Ngo bum E, Njikam N, Okello E, Mcquade, R. 2012. Effect of Mimosa pudica (Linn.) extract on anxiety behaviour and GABAergic regulation of 5-HT neuronal activity in the mouse. J Psychopharmacol. 2012; 26: 575-83.

Baghel A, Rathore DS, Gupta V. Evaluation of diuretic activity of different extracts of Mimosa pudica Linn. Pak J Biol Sci. 2013; 16: 1223-5. 
Berman HM, Westbrook J, Feng Z, Gilliland G, Bhat TN, Weissig H, Shindyalov IN, Bourne PE. The Protein Data Bank. Nucleic Acids Res. 2000; 28: 235-42.

Dash R, Emran TB, Uddin NMM, Islam A, Junaid M. 2014. Molecular docking of fisetin with $\mathrm{AD}$ associated $\mathrm{AChE}, \mathrm{ABAD}$ and BACE1 proteins. Bioinformation. 2014; 10: 562-568.

D Luccia DE. Mimosa pudica, Dionaea muscipula and anesthetics. Plant Signal Behav. 2012; 7: 1163-7.

Franca TC, Guimaraes AP, Cortopassi WA, Oliveira AA, Ramalho TC. Applications of docking and molecular dynamic studies on the search for new drugs against the biological warfare agents Bacillus anthracis and Yersinia pestis. Curr Comput Aided Drug Des. 2013; 9: 50717.

Ganguly M, Devi N, Mahanta R, Borthakur MK. Effect of Mimosa pudica root extract on vaginal estrous and serum hormones for screening of antifertility activity in albino mice. Contraception. 2007; 76: $482-5$.

Harman CA, Turman MV, Kozak KR, Marnett LJ, Smith WL, Garavito RM. Structural basis of enantioselective inhibition of cyclooxygenase-1 by S-alpha-substituted indomethacin ethanolamides. J Biol Chem. 2007; 282: 28096-105.

Hevener KE, Zhao W, Ball DM, Babaoglu K, White SW, Lee RE. Validation of molecular docking programs for virtual screening against dihydropteroate synthase. J Chem Inf Model. 2009; 49: 444-60.

Hristozov DP, Oprea TI, Gasteiger J. Virtual screening applications: a study of ligand-based methods and different structure representations in four different scenarios. J Comput Aided Mol Des. 2007; 21: 617-40.

Husain A, Khan MS, Hasan SM, Alam MM. 2-Arylidene-4-(4phenoxy-phenyl)but-3-en-4-olides: synthesis, reactions and biological activity. Eur J Med Chem. 2005; 40: 1394-404.

Ishikawa TO, Jain N, Herschman, HR. Feedback regulation of cyclooxygenase- 2 transcription ex vivo and in vivo. Biochem Biophys Res Commun. 2009; 378: 534-8

Jiang Q, Ames BN. Gamma-tocopherol, but not alphatocopherol, decreases pro-inflammatory eicosanoids and inflammation damage in rats. Faseb J. 2003; 17: 816-22.

Jones $\mathrm{G}$, Willett $\mathrm{P}$, Glen $\mathrm{RC}$, Leach AR, Taylor $\mathrm{R}$. Development and validation of a genetic algorithm for flexible docking. J Mol Biol. 1997; 267: 727-48.

Kitchen DB, Decornez H, Furr JR, Bajorath J. Docking and scoring in virtual screening for drug discovery: methods and applications. Nat Rev Drug Discov. 2004; 3: 935-49.

Kokane DD, More RY, Kale MB, Nehete MN, Mehendale PC, Gadgoli $\mathrm{CH}$. Evaluation of wound healing activity of root of Mimosa pudica. J Ethnopharmacol. 2009; 124: 311-5.

Kurumbail RG, Stevens AM, Gierse JK, Mcdonald JJ, Stegeman RA, Pak JY, Gildehaus D, Miyashiro JM, Penning TD, Seibert K, Isakson PC, Stallings WC. Structural basis for selective inhibition of cyclooxygenase-2 by anti-inflammatory agents. Nature. 1996; 384: 644-8.

Lanza FL. A guideline for the treatment and prevention of NSAID-induced ulcers. Members of the Ad Hoc Committee on Practice Parameters of the American College of Gastroenterology. Am J Gastroenterol. 1998; 93: 2037-46.

Llorens O, Perez JJ, Palomer A, Mauleon D. Differential binding mode of diverse cyclooxygenase inhibitors. J Mol Graph Model. 2002; 20: 359-71.

Luong C, Miller A, Barnett J, Chow J, Ramesha C, Browner MF. Flexibility of the NSAID binding site in the structure of human cyclooxygenase-2. Nat Struct Biol. 1996; 3: 927-33.

Malayan J, Selvaraj B, Warrier A, Shanmugam S, Mathayan M, Menon T. Anti-mumps virus activity by extracts of Mimosa pudica, a unique Indian medicinal plant. Indian J Virol. 2013; 24: 166-73.

Metwally KA, Yaseen SH, Lashine EL, El-fayomi, HM, Elsadek ME. Non-carboxylic analogues of arylpropionic acids: synthesis, anti-inflammatory activity and ulcerogenic potential. Eur J Med Chem. 2007; 42: 152-60.
Michaux C, Charlier C. Structural approach for COX-2 inhibition. Mini Rev Med Chem. 2004; 4: 603-15.

Molina M, Contreras CM, Tellez-Alcantara P. Mimosa pudica may possess antidepressant actions in the rat. Phytomedicine. 1999; 6: 319-23.

Ngo bum E, Dawack DL, Schmutz M, Rakotonirina A, Rakotonirina SV, Portet C, Jeker A, Olpe HR, Herrling P. Anticonvulsant activity of Mimosa pudica decoction. Fitoterapia. 2004; 75: 309-14.

Osolodkin DI, Palyulin VA, Zefirov NS. Structure-based virtual screening of glycogen synthase kinase 3- $\beta$ inhibitors: analysis of scoring functions applied to large true actives and decoy sets. Chem Biol Drug Des. 2011; 78: 378-90.

Pouplana R, Lozano JJ, Ruiz J. Molecular modelling of the differential interaction between several non-steroidal anti-inflammatory drugs and human prostaglandin endoperoxide $\mathrm{H}$ synthase-2 (h-PGHS-2). J Mol Graph Model. 2002; 20: 329-43.

Sanberg PR. Neural capacity in Mimosa pudica: a review. Behav Biol. 1976; 17: 435-52.

Shrinivasan M, Skariyachan S, Aparna V, Kolte VR. Homology modelling of CB1 receptor and selection of potential inhibitor against Obesity. Bioinformation. 2012; 8: 523-8.

Smith CJ, Morrow JD, Roberts LJ, Marnett LJ. Differentiation of monocytoid THP-1 cells with phorbol ester induces expression of prostaglandin endoperoxide synthase-1 (COX-1). Biochem Biophys Res Commun. 1993; 192: 787-93.

Smith WL, Dewitt DL, Garavito RM. Cyclooxygenases: structural, cellular, and molecular biology. Annu Rev Biochem. 2000; 69: 145-82.

Tsurumi S, Asahi Y. Identification of jasmonic acid in Mimosa pudica and its inhibitory effect on auxin- and light-induced opening of the pulvinules. Physiologia Plantarum. 1985; 64: 207-211.

Uddin MMN, Emran TB, Mahib MM, Dash R. Molecular docking and analgesic studies of Erythrina variegatas derived phytochemicals with COX enzymes. Bioinformation. 2014; 10: 630-6.

Vaidya GH, Sheth UK. Mimosa pudica (linn.) its medicinal value and pilot clinical use in patients with menorrhagia. Anc Sci Life. 1986; 5: 156-60.

Vane JR, Bakhle YS, Botting RM. Cyclooxygenases 1 and 2. Annu Rev Pharmacol Toxicol. 1998; 38: 97-120.

Varin L, Chamberland H, Lafontaine JG, Richard M. The enzyme involved in sulfation of the turgorin, gallic acid 4-O-(beta-Dglucopyranosyl-6'-sulfate) is pulvini-localized in Mimosa pudica. Plant J. 1997; 12: 831-7.

Zhang J, Yuan K, Zhou WL, Zhou J, Yang P. Studies on the active components and antioxidant activities of the extracts of Mimosa pudica Linn. from southern China. Pharmacogn Mag. 2011; 7: 35-9.

\section{How to cite this article:}

Ashekul Islam, Mohammad Shah Hafez Kabir, Raju Dash, Talha Bin Emran, Md. Zia Uddin, Khairun Nesa, Mir Muhammad Nasir Uddin and Md. Tanveer Ahsan. Virtual screening for potential COX-inhibiting constituents from Mimosa pudica. J App Pharm Sci, 2015; 5 (07): 071-075. 